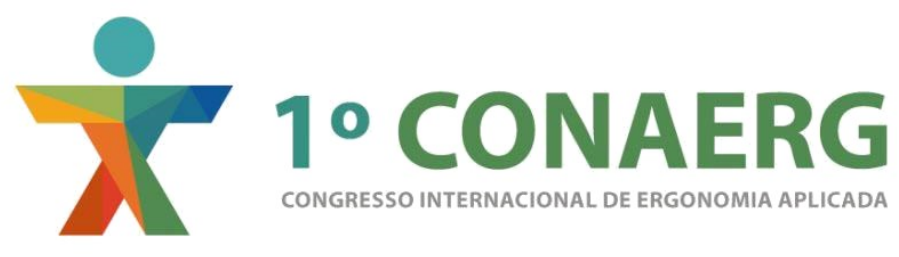

\title{
TESTE DE USABILIDADE EM VEÍCULOS OFF-ROAD: ESTUDO DE CASO COM BAJAS
}

\author{
Gabriel Henrique Cruz Bonfim (1); \\ Erica Pereira das Neves (2); \\ Beatriz Macarini Mangialardo (3); \\ Renato dos Santos Pinto (4); \\ Fauto Orsi Medola (5); \\ Luis Carlos Paschoarelli (6)
}

(1) UNESP - Univ. Estadual Paulista, Doutorando

e-mail: gh cb@hotmail.com

(2) UNESP - Univ. Estadual Paulista, Doutoranda

e-mail: ericapneves@yahoo.com.br

(3) UNESP - Univ. Estadual Paulista, Graduanda

e-mail: beatrizmacarinimangialardo@gmail.com

(4) UNESP - Univ. Estadual Paulista, Graduando

e-mail: renatodi07@gmail.com

(5) UNESP - Univ. Estadual Paulista, Doutor

e-mail: fausto.medola@faac.unesp.br

(6) UNESP - Univ. Estadual Paulista, Livre Docente

e-mail: paschoarelli@faac.unesp.br

\begin{abstract}
RESUMO
O presente estudo baseou-se em um teste de usabilidade com usuários universitários e experientes na condução de veículos bajas. Os objetos de estudo foram dois bajas desenvolvidos pela equipe PAC Baja da Unesp-Bauru. O objetivo foi identificar possíveis diferenças quanto à configuração dos veículos, levando em consideração os critérios de engenharia e design. Os resultados apontam que não houve diferença entre os produtos avaliados, o que levou a equipe a iniciar o desenvolvimento de um novo baja com ênfase nas deficiências encontradas no estudo.
\end{abstract}

\section{ABSTRACT}

This study was based on a usability test with university students, who were experienced in conducting bajas. The objects of study were two bajas developed by the team PAC Baja from Unesp-Bauru. The aim was to identify potential differences in the configuration of the vehicle, taking into account the engineering and design criteria. The results showed that there was no difference between the products, which led the team to start the development of a new baja emphasizing the shortcomings found in the study. 


\section{INTRODUÇÃO}

A competição Baja SAE (Society of Automotive Engineers) envolve projetos e a construção de veículos off-road que desafiam alunos de engenharia de todo o mundo, a aplicarem na prática conhecimentos adquiridos dentro das salas de aula. Os alunos, organizados em equipes, representam diferentes Instituições de Ensino Superior, e devem se envolver em todas as etapas de desenvolvimento do veículo, desde sua concepção e detalhamento de projeto até a sua construção final e testes (SAE BRASIL, 2010).

A primeira edição do evento ocorreu no ano de 1976, na Universidade do Sul da Califórnia, nos Estados Unidos, sob orientação do Dr. John F. Stephens e, desde então, a competição vem crescendo, estando presente em diversos países. No Brasil, o projeto chegou em 1994, com o nome de Projeto (ou Competição) SAE BRASIL, e envolve etapas regionais pelo país (Sul, Sudeste e Nordeste) e uma etapa nacional, na qual participam os melhores classificados nas etapas regionais (SAE BRASIL, 2010; SILVA, et al. 2013).

A competição baseia-se na disputa comparativa entre os veículos desenvolvidos pelas equipes inscritas, principalmente no que se refere às soluções tecnológicas e estruturais desenvolvidas e adotadas frente ao regulamento e, naturalmente, sua performance em campo (atividade real). Dentre as diretrizes apresentadas no regulamento, destaca-se a dimensão e configuração do veículo, que determinam que o Baja deve possuir no mínimo 4 rodas, ser capaz de transportar pessoas com até 1,90m e 113,4kg, e não apresentar largura e comprimento superiores a $1620 \mathrm{~mm}^{2} 2750 \mathrm{~mm}^{1}$, respectivamente (SAE BRASIL, 2016a).

O veículo também deve ser capaz de operar sobre terrenos acidentados e com obstáculos, tais como pedra, lama, grandes desníveis topográficos, entre outros, independentemente das condições climáticas. No caso do motor, a organização do evento determina o mesmo modelo para todos as equipes, sendo obrigatório sua apresentação com todas as características originais.

A avaliação das equipes e dos veículos ocorre em duas partes: Avaliação Estática e Avaliação Dinâmica. A Avaliação Estática é subdividida em três partes: 1) Inspeção Técnica e de Segurança, que visa determinar se o veículo e o equipamento de apoio satisfazem os requisitos mínimos de configuração e segurança descritos no regulamento; 2) Verificação de Motor; e, 3) Avaliação de Projeto, que considera o Relatório de Projeto, Apresentação de Projeto e Final de Projeto. Já as avaliações dinâmicas envolvem o desempenho do veículo em diversas condições, sendo analisados fatores tais como aceleração, velocidade máxima, tração e suspensão, capacidade de manobra e enduro de resistência. Essa última, contempla o número de voltas em uma pista irregular, off-road, com obstáculos e em qualquer condição climática, por um período de 4 horas. O número de voltas no período estabelecido determina a pontuação, a qual é vulnerável às punições em caso de irregularidades (SAE BRASIL, 2016b).

$\mathrm{Na}$ etapa classificatória, que ocorre por meio da Avaliação Estática, itens como segurança e conforto do operador também são avaliados. Nesses quesitos, os aspectos relativos à interação piloto $x$ veículo são itens importantes para o bom julgamento do veículo, uma vez que são considerados fatores tais como ergonomia, esforços de pilotagem (volante e pedais de acionamento de aceleração e frenagem), vibrações, dirigibilidade, acessibilidade aos comandos, entre outros (SAE BRASIL, 2016b). 
Por norma, a competição permite que cada instituição utilize o mesmo carro por dois anos. Essa limitação gera o desafio às equipes de inovarem seus veículos com base no aprimoramento de seus conhecimentos em engenharia. Esse processo contribui para o desenvolvimento de novos projetos e tecnologias, os quais, cada vez mais, respaldam sobre a importância de se promover a integração não apenas dos conhecimentos de engenharia, mas sim de outras áreas dos saberes, tal como o Design.

O Design, por sua característica multi e interdisciplinar, proporciona ferramentas que contribuem para a verificação e resolução de problemas ligados ao desenvolvimento de um novo produto (SCHULMANN, 1994). Sua permeabilidade dentre diferentes saberes visa atender às necessidades e expectativas dos usuários, por meio de soluções que integrem tanto aspectos técnicos e funcionais, como estéticos, simbólicos e visuais. Assim, uma vez que trabalha sobre a perspectiva humana, critérios ergonômicos e de usabilidade são essenciais para o desenvolvimento de produtos que sejam satisfatórios aos usuários mediante seu bom desempenho técnico, funcional e estético.

Na perspectiva dos veículos Baja, a identificação e compreensão dos fatores ergonômicos e de usabilidade podem contribuir para o aprimoramento do projeto dos futuros veículos, tanto com relação ao conforto do piloto bem como para o melhor desempenho do carro durante a prova de enduro. A integração de diferentes áreas do saber, focando o mesmo objeto e objetivo, contribui para a descoberta e a verificação de diferentes fatores que caracterizam a integração do usuário com o veículo. Portanto, o presente estudo teve por objetivo identificar as possíveis diferenças no que diz respeito à configuração de dois veículos Baja, levando em consideração, principalmente, critérios de engenharia e design, por meio de um teste de usabilidade.

\section{USABILIDADE}

Pela definição da norma ISO 9241-11, usabilidade é uma "medida na qual um produto pode ser usado por usuários específicos para alcançar objetivos específicos com eficácia, eficiência e satisfação em um contexto específico de uso" (ABNT, 2002).

Inicialmente, a usabilidade se destacou entre ergonomistas que estavam envolvidos com projetos de computadores e programas mas, com o passar dos tempos, também passou a ser objeto de estudo de outras áreas (JORDAN et al. 1996), deixando de se preocupar apenas com os aspectos da interface, mas considerando tanto o desempenho humano quanto os aspectos subjetivos da percepção humana (DILLON, 2001; HAN et al. 2001).

Para a avaliação da usabilidade, é importante que os objetivos estejam bem definidos e seus componentes estejam bem descritos, tais como os usuários, a tarefa, os equipamentos e o ambiente. Em relação aos usuários é importante que se saiba suas habilidades, experiência em relação ao produto, educação, atributos físicos, capacidades sensoriais e motoras. Com relação à tarefa, é importante o detalhamento das atividades e processos envolvidos em seu desempenho. Para os equipamentos são importantes as características mais relevantes para o estudo. Já para o ambiente importa as características e atributos de ambientes técnico, físico, atmosférico, cultural e social (ABNT, 2002).

\subsection{Medidas de Usabilidade}

De acordo com a ABNT (2002), as medidas de usabilidade são eficácia, eficiência e satisfação. É comum que sejam consideradas certas diretrizes para o cálculo de cada uma dessas medidas, no entanto, não existe uma regra geral da maneira como são escolhidas ou combinadas. De maneira geral, considera-se: 
- Eficácia como os "objetivos do usuário quanto à precisão e completude com que estes objetivos podem ser alcançados".

- Eficiência como o nível de eficácia relacionado ao consumo de recursos, como por exemplo esforço físico ou mental, tempo, custos materiais ou financeiros.

- Satisfação como "a extensão pela qual os usuários estão livres de desconforto e suas atitudes em relação ao uso do produto" (ABNT, 2002).

Uma das possibilidades de cálculo para a eficácia e eficiência pode ser encontrada em Bevan e Macleod (1994). Os autores apontam que a eficácia depende do número de tarefas completadas considerando a qualidade de como os objetivos são atingidos, ou seja, para cálculo da eficácia deve-se considerar tanto a quantidade como a qualidade da completude das tarefas.

Com relação à eficiência, Bevan e Macleod (1994) sugerem que o cálculo dessa medida pode ser definido pela eficácia sobre a quantidade de esforço realizado; ou sobre o tempo de realização da tarefa.

Já a satisfação exige uma atenção maior, pois esta é uma medida subjetiva. Atualmente, existem vários métodos de avaliação dos aspectos satisfatórios e insatisfatórios da interação do usuário com o produto, boa parte desses métodos pode ser encontrada em Tulis e Albert (2008). Entretanto, a maioria desses protocolos e questionários destinam-se a avaliação de sistemas informacionais, dessa forma, ao considerar as interações "usuário X produto", o System Usability Scale (SUS) tem se apresentado como o mais apropriado a ser aplicado. Apesar de nunca ter passado por qualquer processo formal de normalização, a ferramenta SUS é muito bem aceita e traz resultados satisfatórios, sendo incorporada em kits de ferramentas de avaliação de usabilidade e várias publicações se referem ao SUS como "padrão da indústria" (BROOKE, 2013).

O protocolo de avaliação SUS consiste em 10 sentenças acompanhadas de uma escala de Likert, na qual o participante aponta o seu nível de concordância com o que está sendo dito. Ao todo são cinco sentenças com peso positivo em relação ao produto e cinco com peso negativo. Dependendo do nível de concordância do usuário, cada sentença pode receber uma pontuação que varia de 0 a 4 pontos. No final, soma -se os pontos de todas as sentenças e multiplica-se por 2,5. O resultado final é o nível de satisfação expresso em porcentagem (TULLIS e ALBERT, 2008).

\section{BAURU NA COMPETIÇÃO: O ESTUDO DOS BAJAS}

A Faculdade de Engenharia (Unesp- Bauru) está envolvida nas competições Baja SAE Brasil desde da estreia da modalidade no país. Desde então, diversas equipes representaram a Instituição e compartilharam do empenho de desenvolver veículos com qualidades técnicas, funcionais e estéticas que pudessem, progressivamente, melhorar o desempenho dos bajas nas competições.

Desde 2007, a equipe "PAC Baja" assumiu os projetos e o desenvolvimento dos veículos, bem como intensificou a participação da Instituição nas competições nacionais. A equipe é composta, atualmente, por 47 membros, dentre eles estudantes de cursos tais como, Engenharia Mecânica, Engenharia Elétrica, Engenharia de Produção, Design, Relações Públicas e Jornalismo. O caráter multi e interdisciplinar da equipe contribui para a troca de informações bem como corrobora para a formação de um saber técnico mais apurado e criativo.

Os últimos dois protótipos desenvolvidos remontam aos anos de 2013 e 2015, e, no presente estudo, serão objetos de estudo. Para diferenciá -los, optou-se pelas seguintes denominações: Baja Antigo (BA; ano 2013) e Baja Novo (BN; ano 2015) (Figura 1). 
As avaliações e o desempenho do BA nas competições dos anos de 2013 e 2014 serviram de base para o projeto de um novo veículo. Sob a perspectiva da inovação, a equipe PAC Baja lançou mão de conhecimentos teóricos e técnicos e promoveu alterações técnicas e de desenho que foram significativas à construção do BN. Dentre elas pode-se citar, especialmente, a redução das dimensões do veículo e da massa; a aplicabilidade de materiais mais leves e resistentes; e a readequação de processos e técnicas de fabricação bem como de aplicação dos materiais.

Figura 1 - Baja antigo e Baja novo

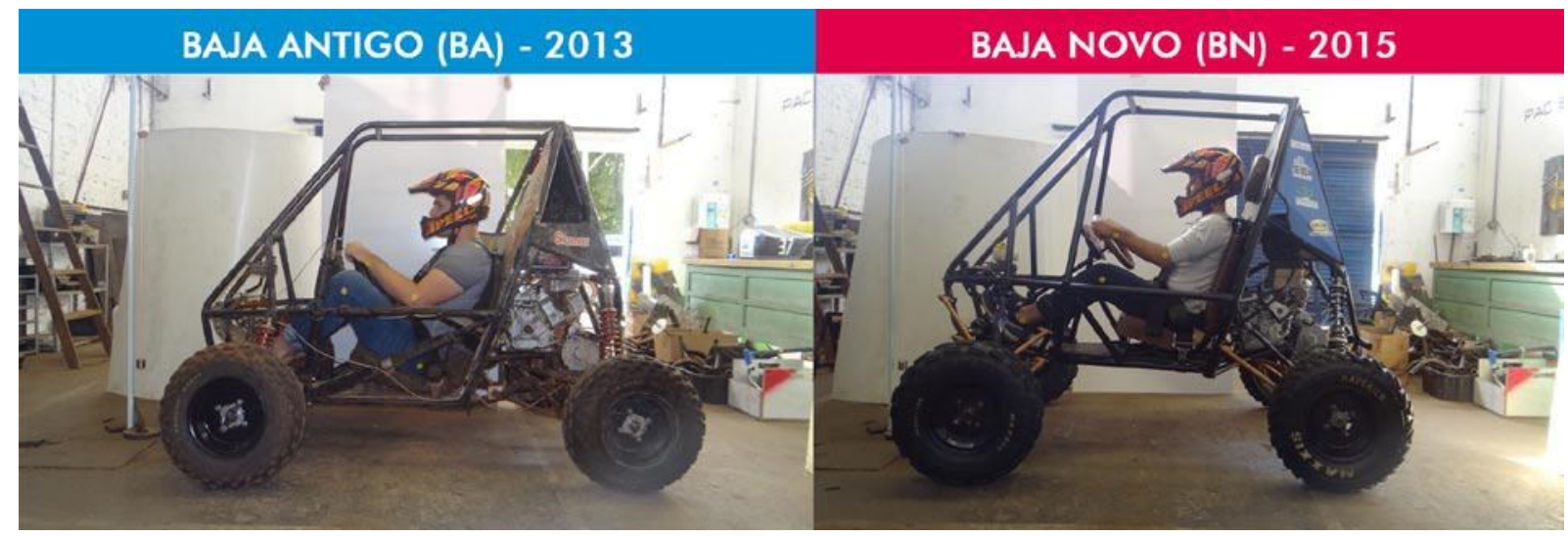

Fonte: autoria própria

A dimensão do veículo influencia consideravelmente em sua performance na prova de enduro, principalmente durante curvas e manobras que exijam mais esforço e agilidade do veículo. Sendo assim, o modelo mais novo foi redimensionado, e apresentou medidas menores em comparação ao modelo antigo. Essa alteração foi acompanhada pela redução dos travamentos estruturais na traseira e a compactação dos elementos do motor. A redução de toda massa da gaiola, propiciou assim, a redução de massa da nova gaiola.

Consequentemente, houve a reformulação e o redesenho do chapéu (ou teto) do BN. No BA, este elemento apresentava um chapéu superdimensionado que dificultava a visão do piloto assim como a ação de entrar e sair do carro. Evidencia-se que, de acordo com o Regulamento SAE para a competição, os pilotos devem realizar a atividade de sair do veículo em cinco segundos. A partir disso, optou-se por um desenho de chapéu reduzido que oferecesse maior campo de visão ao piloto e total liberdade para entrar e sair do veículo (Figura 2).

Outra alteração foi quanto a fabricação da nova capa do CVT (Transmissão Continuamente Variável), a qual tem a função de proteção da transmissão do veículo contra lama, pedregulhos e demais elementos que podem apresentar riscos a transmissão. O uso da fibra de vidro se manteve, contudo, uma nova técnica de modelagem foi empregada, possibilitando a confecção de uma capa mais fina e resistente às altas temperaturas. Essa nova técnica contribuiu também para a leveza do carro, uma vez que implicou na redução de $1,04 \mathrm{~kg}$ em relação ao peso da capa do BA.

No que diz respeito a carenagem, tanto o material quanto sua espessura foram alterados na fabricação do BN. Para o modelo mais antigo foi utilizado o PS de espessura de $1 \mathrm{~mm}$, enquanto para o modelo mais novo empregou-se o PVC expandido de $2 \mathrm{~mm}$ (laterais do veículo) e $3 \mathrm{~mm}$ de espessura (dianteira do veículo). Essa troca proporcionou ao BN maior resistência, principalmente em relação a parte dianteira. Além disso, o desenho do BN foi desenvolvido seguindo referências estéticas e simbólicas, no caso, o F-Type Project 7, carro de edição limitada desenvolvido pelo designer de carros esportivos da montadora Jaguar, César Pieri, ex-aluno da Unesp- Bauru. A escolha da referência serviu de inspiração à 
equipe, dado o relacionamento de César Pieri com a Unesp, estimulando, assim, o desenho de um carro mais atrativo aos olhos por meio de qualidades estéticas e simbólicas. Além disso, a equipe pode prestar suas homenagens ao ex-aluno.

Seguindo a referência dos painéis antigos da Jaguar, o painel do BN foi produzido com eucalipto de reflorestamento, substituindo o antigo modelo feito de alumínio. Além disso, o painel e, consequentemente o travamento da direção, foi instalado mais abaixo em comparação ao painel antigo, o que ampliou o campo de visão do piloto.

No banco, a exemplo do F-Type Project 7, foram desenhados losangos sobre o courvin marrom (sintético). Além disso, princípios ergonômicos influenciaram o novo posicionamento do banco, no qual encosto e assento receberam novas inclinações na perspectiva de oferecer maior conforto ao piloto.

Diferentemente do BA, o projeto do banco do BN também se destacou pela aplicação de diferentes densidades de espuma em partes distintas do encosto e do assento. Camadas de espuma de D33 foram utilizadas na região de contato da área poplítea do piloto (assento) e na região superior das costas (encosto). Na região posterior da coxa e na lombar foi utilizado espuma mais densa, D45.

Destaca-se que as novas atribuições estéticas e materiais foram perceptivas aos juízes que avaliaram o BN na competição do ano de 2015. Essa avaliação agregou valor ao projeto e intensificou a importância dos elementos estéticos e simbólicos aplicados no veículo.

Figura 2 - Baja antigo e Baja novo: diferenças no projeto

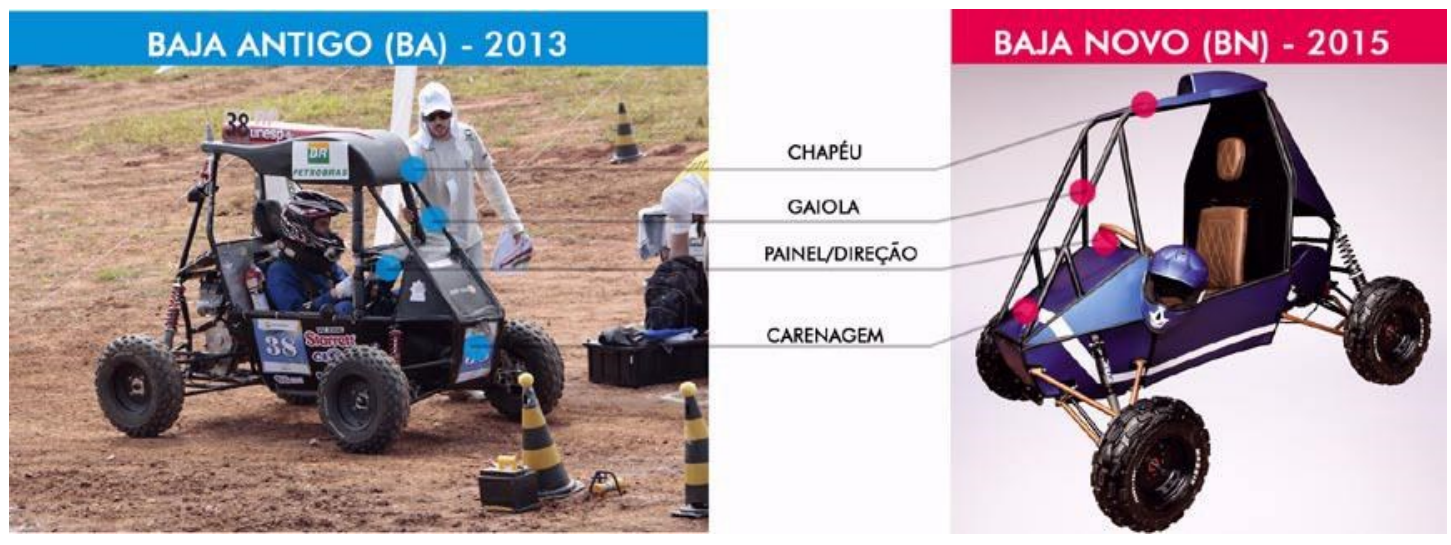

Fonte: autoria própria

\section{MATERIAIS E MÉTODOS}

\subsection{Aspectos Éticos}

Por envolver seres humanos nos testes, o presente estudo buscou atender a Resolução 466/12- CNSMS e o "Código de Deontologia do Ergonomista Certificado - Norma ERG BR 1002 - ABERGO" (ABERGO, 2003), para tanto foi aplicado um Termo de Consentimento Livre e Esclarecido (TCLE) o qual foi lido e preenchido por todos os participantes do teste. 


\subsection{Sujeitos}

Participaram, desse estudo, catorze sujeitos experientes que já haviam dirigido várias vezes os bajas. A amostragem foi baseada em Nielsen (1993) e Tullis e Albert (2008), os quais apresentam amostras de 6 a 12 pessoas como suficientes.

\subsection{Materiais}

Foi aplicado um protocolo de identificação com os participantes para obtenção do nome, idade, lateralidade, curso, altura, peso e sintomas musculoesqueléticos apresentados nos últimos 12 meses.

Como já comentado, os produtos avaliados foram dois bajas (Figura 1) construídos pela equipe PAC Baja da Unesp-Bauru, ambos já utilizados em competições, sendo um mais antigo (ano 2013) e outro mais recente (ano 2015).

Foi utilizado um GPS para o cálculo da distância do trajeto que os participantes iriam percorrer, um cronômetro para mensuração do tempo de realização das tarefas e uma câmera GoPro Hero 4 presa aos veículos para a gravar os sujeitos percorrendo o percurso estabelecido.

Além disso, para a análise da satisfação, os autores elaboraram um protocolo SUS baseado nos critérios de avaliação nas competições de bajas. Ao todo foram dez sentenças que abordaram questões de segurança, facilidade para entrar e sair do veículo, acionamento do volante, conforto do suporte postural, condições de visibilidade, vibração, estabilidade, acessibilidade aos comandos (volante e pedais), desempenho do veículo (aceleração, frenagem, curvas) e acionamento dos pedais.

\subsection{Procedimentos}

Inicialmente, todos os sujeitos que aceitaram participar do estudo faziam uma volta de reconhecimento no percurso estipulado para a realização da tarefa. O percurso foi realizado uma estrada de terra de 1,6 km localizada dentro das dependências do Campus da UnespBauru.

Após a volta de reconhecimento, os participantes liam, preenchiam e assinavam o TCLE e logo na sequência, completavam o protocolo de identificação.

Então, os procedimentos do teste de usabilidade eram explicitados aos indivíduos. Após a explicação, o sujeito vestia todos os equipamentos obrigatórios para a segurança do baja como capacete, óculos e restritores para que os braços não fossem colocados para fora do veículo. Depois disso, o sujeito se posicionava no interior do primeiro baja, o qual já se encontrava no início do percurso, e assim os restritores eram presos ao volante e o cinto de segurança era preso e afivelado.

$\mathrm{Na}$ sequência, era dada a largada e o sujeito deveria realizar a tarefa estipulada para o estudo que consistia em percorrer o trajeto no menor tempo possível. O tempo era contado desde a largada até a parada total do veículo ao final do percurso.

Ao terminar a tarefa, o sujeito saía do baja, tirava os equipamentos de segurança e sentavase à uma mesa para responder o protocolo SUS, o qual era preenchido de acordo com a experiência com o produto que ele acabara de usar.

Por fim, os mesmos procedimentos se repetiam para o segundo veículo avaliado. Cabe ressaltar que a ordem dos veículos foi randomizada para todos os sujeitos participantes. 


\subsection{Análise dos Dados}

Terminados os testes, os tempos foram contabilizados e as tarefas, desvios e erros foram descritos com a ajuda dos vídeos.

Seguindo a norma da ABNT (2002), foram avaliadas a eficácia, eficiência e satisfação. Para análise da eficácia foi considerada a tarefa completada com sucesso (percorrer o trajeto no menor tempo possível). Para a análise da eficiência, foi considerado o tempo total de execução da tarefa em relação ao tempo do participante que conseguiu realizar a tarefa mais rápido. Para a análise de satisfação, o Protocolo SUS foi analisado de acordo com os procedimentos descritos em Tullis e Albert (2008). Também foram analisados individualmente cada um dos itens do protocolo SUS, uma vez que para a área do Design do Produto, as análises individuais podem contribuir na elaboração dos requisitos de projeto.

Todos os outros dados foram tabulados em planilhas eletrônicas para cálculo de média e desvio padrão. Gráficos foram gerados para melhor apresentação, visualização e compreensão dos resultados. Testes estatísticos foram realizados para verificação de diferenças significativas entre os conjuntos de dados. Os procedimentos de análise basearam-se na verificação de normalidade, segundo o teste de Shapiro-Wilk; e homogeneidade, segundo o teste de Levene. Para os casos que apresentaram normalidade e homogeneidade, foram aplicados testes paramétricos (ANOVA), a inobservância de normalidade OU homogeneidade implicou a aplicação de testes não paramétricos (Wilcoxon).

\section{RESULTADOS E DISCUSSÃO}

A idade média dos participantes foi de 23,14 anos com um desvio padrão de 2,98 . Todos os sujeitos eram do gênero masculino, sendo 13 destros e 1 canhoto. Todos os participantes eram estudantes de graduação, dos quais nove (64\%) cursavam Engenharia Mecânica, três (22\%) eram alunos de Design, um (7\%) cursava Engenharia de Produção, e um (7\%) era aluno de Engenharia Elétrica. Apenas três (22\%) relataram ter apresentado algum sintoma musculoesquelético no último ano, e destes, somente um $(7 \%)$ precisou de tratamento médico.

Com relação às medidas de usabilidade, sabe-se que estas são: eficácia, eficiência e satisfação, as quais serão abordadas individualmente a seguir.

\section{$5.1 \quad$ Eficácia}

Para o presente estudo, as medidas de eficácia foram consideradas de acordo com a precisão e completude com que os sujeitos conseguiram alcançar o objetivo da tarefa, o qual consistia em percorrer o trajeto estipulado no menor tempo possível.

Observou-se que todos os sujeitos realizaram a tarefa sem erros ou desvios com ambos os veículos. Isso se deve ao fato de que todos os participantes já estavam familiarizados com os bajas e também já haviam realizado uma volta de reconhecimento na pista. Portanto, a eficácia para os dois objetos de estudo foi de $100 \%$.

\subsection{Eficiência}

A análise da eficiência foi realizada relacionando o nível de eficácia alcançada com o consumo de tempo. Como a eficácia, para ambos os bajas, foi de $100 \%$; considerou-se o menor tempo de realização da tarefa como sendo o tempo ideal, ou seja, esse tempo foi considerado como $100 \%$ de eficiência, e a partir dele os demais níveis de eficiência foram calculados, ou seja, quanto menor o tempo, maior a eficiência. 
A Figura 2 mostra um gráfico comparativo dos tempos de realização da tarefa para ambos os veículos utilizados no teste.

Figura 2 - Comparação dos tempos de realização da tarefa

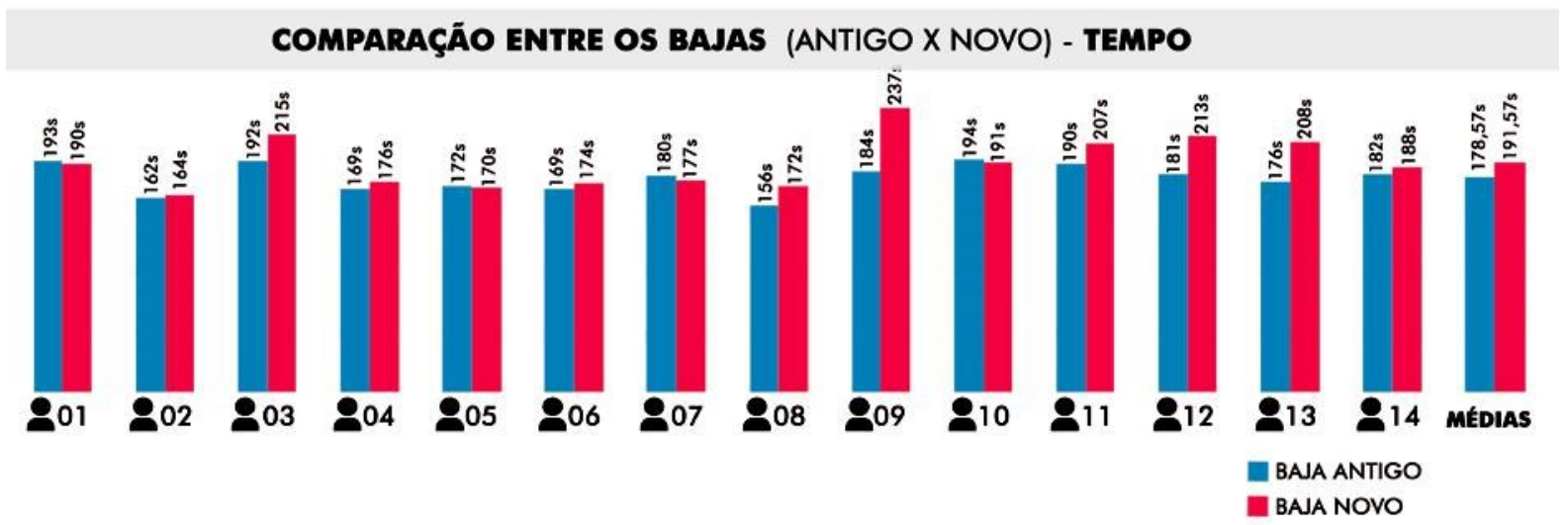

Fonte: autoria própria

Por meio da Figura 2 é possível observar que o Baja antigo possibilitou a realização da tarefa em menos tempo. Apenas dois sujeitos realizaram a tarefa em menos tempo com o baja novo. Em se tratando das médias, o desvio padrão do baja antigo foi de $11,84 \mathrm{~s}$, e do baja novo foi de $21,43 \mathrm{~s}$. Cabe ressaltar que houve diferença significativa $(p \leq 0,05)$ entre as médias, o que já era esperado, visto que se trata de veículos utilizados em corrida, onde o tempo é crucial para o resultado.

Portanto, verificou-se que a eficiência do baja antigo foi de $88 \%$ (d.p. 5,99), enquanto que a do baja novo foi de $82 \%$ (d.p. 8,79). Os valores da eficiência em porcentagem estão apresentados na Figura 3.

Figura 3 - Comparação do nível de eficiência entre os bajas

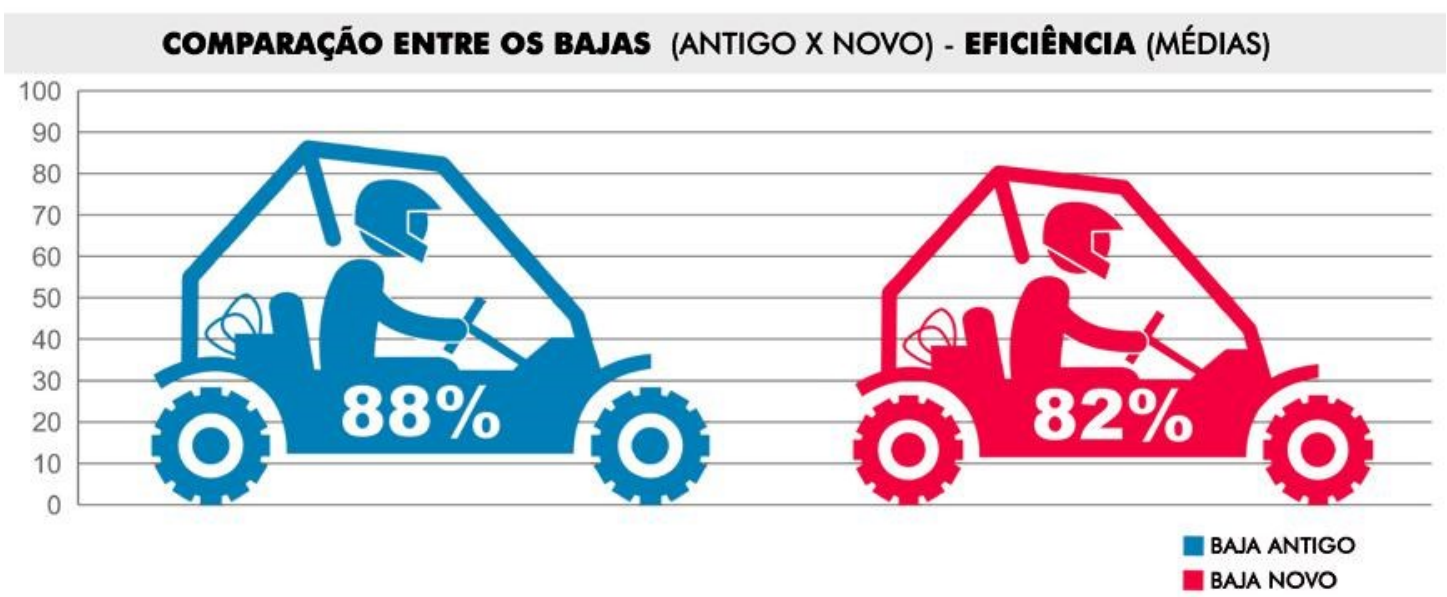

Fonte: autoria própria

\subsection{Satisfação}

Para avaliar a satisfação foi utilizado o protocolo SUS, o nível de satisfação foi calculado segundo as recomendações de Tullis e Albert (2008). Os resultados são apresentados na Figura 4. 
Figura 4 - Comparação do nível de satisfação entre os bajas (SUS)
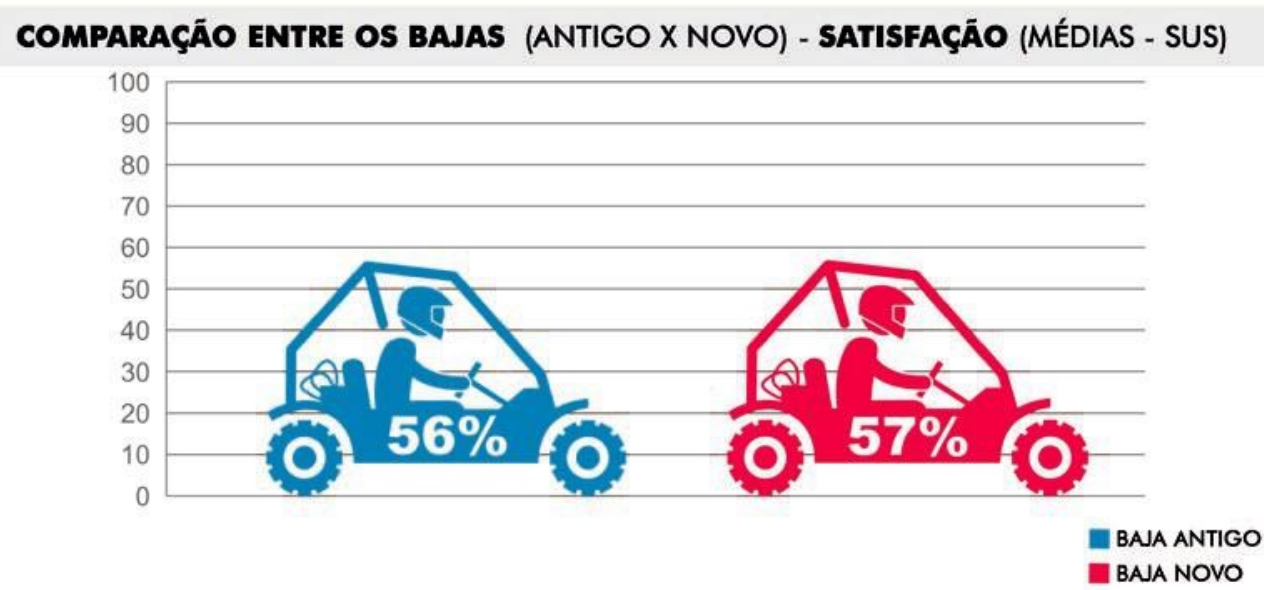

Fonte: autoria própria

Nota-se que o baja novo apresentou um nível de satisfação (57\%) maior que o baja antigo (56\%), no entanto não houve diferença significativa entre essas médias. Segundo Tullis e Albert (2008), esses níveis de satisfação indicam que os objetos de estudo não estão dentro dos padrões ideais, sendo ainda precários. De acordo com os autores, médias de satisfação abaixo dos $60 \%$ são consideradas relativamente precárias, enquanto aquelas acima de $80 \%$ podem ser consideradas muito boas.

No que se refere aos aspectos avaliados pelo protocolo (Figura 5), no quesito visibilidade, o BN apresentou melhor satisfação se comparado ao BA. Esse resultado pode estar relacionado às diferenças atribuídas ao desenho e configuração do novo carro, tal como redução do chapéu e o rebaixamento do painel e do travamento de direção, estratégias essas que possibilitaram maior campo de visão ao operador. Além disso, o posicionamento do assento e encosto do BN exige uma postura mais ereta do operador, contribuindo com um melhor campo visual. Contudo, tal posição exige mais esforço e tensão muscular, o que pode ter contribuindo para que os níveis de satisfação fossem menores que os indicados no BA.

Figura 5 - Comparação do nível de satisfação por quesitos

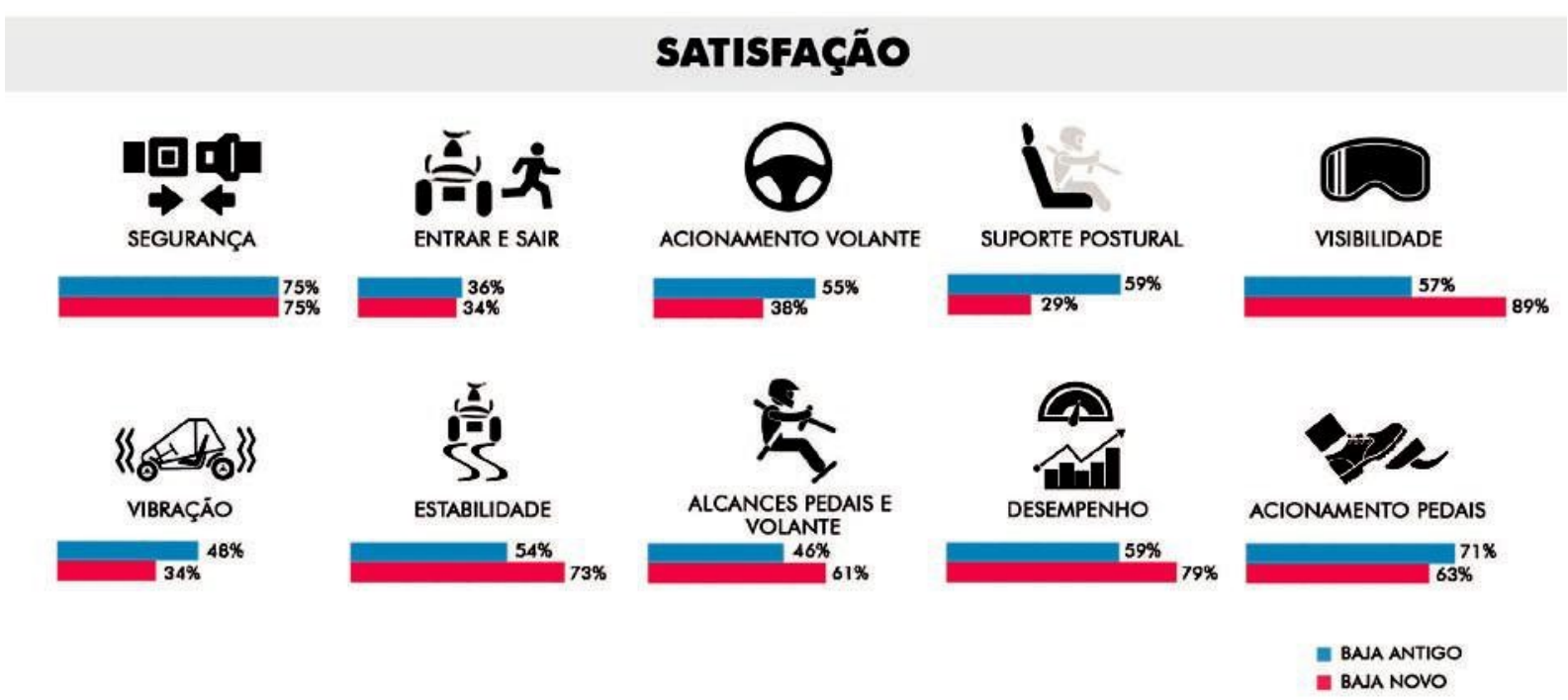

Fonte: autoria própria 
Apesar de em estudo prévio o BA ter apresentado altos índices de desconforto percebido, principalmente nas regiões do quadril e da lombar (IKEDA et al., 2011), seu suporte postural apresentou maiores níveis de satisfação. Esse resultado também pode estar associado ao fato do BA ter mostrado maior satisfação quanto à vibração. Isso porque a vibração a qual o veículo expõe o operador provoca desconforto e, em casos mais graves, dores e problemas de saúde, especialmente quando considerado veículos off-road (MANSFIELD, 2013).

Evidencia-se que a posição dos quadris e dos olhos são usadas como referência para o desenvolvimento dos assentos ergonômicos, uma vez que são importantes para a acomodação, alcance, visibilidade, conforto, segurança, performance e conveniência do usuário (PARK et al., 2013; GYI, 2013). Quando o assento é bem concebido, o peso do tronco é sustentado pelo encosto, fazendo com os músculos da coluna relaxem e a curva da coluna lombar seja suportada, do contrário, a pressão e o mal posicionamento da coluna pode acarretar diversos problemas à saúde do operador (GYI, 2013).

Quanto ao desempenho e a estabilidade, o BN mostrou índices maiores de satisfação, resultado que pode estar associado à redução de sua massa e de suas dimensões. Já os critérios de acionamento do volante e acionamento dos pedais, a satisfação dos usuários é maior para o baja antigo, resultado esse que também pode estar relacionado ao seu suporte postural.

\section{$5.4 \quad$ Síntese dos resultados}

De maneira geral pôde-se observar que não houve diferenças significativas entre os bajas avaliados quanto à eficácia e satisfação. A diferença só foi observada em relação à eficiência que foi maior para o baja antigo. Uma possível explicação para esse fato pode ser encontrada no melhor conforto oferecido pelo seu suporte postural, menos vibração e melhor acessibilidade ao volante e aos pedais. Como já observado por lida (2005), quanto maior for o nível de conforto oferecido por um produto, melhor será o desempenho do usuário ao utilizá- lo. No entanto, com base na totalidade dos resultados não foi possível afirmar que o baja antigo é melhor em termos de usabilidade que o baja novo.

\section{CONCLUSÃO}

O presente estudo avaliou a usabilidade de dois diferentes bajas utilizados em competição. Os resultados mostram que não houve diferenças significativas quanto à eficácia e satisfação, apenas quanto à eficiência. No entanto, os níveis de satisfação encontram-se abaixo dos padrões desejáveis. Desse modo, não se pode afirmar que um veículo é realmente melhor que o outro, e devido a esse fato a equipe responsável pela construção e adequação dos bajas resolveu desenvolver um novo carro buscando atentar a critérios ergonômicos que visam a melhoria do suporte postural, dos alcances do volante e dos pedais, o desenvolvimento de um novo volante mais confortável, e a diminuição das vibrações, ou seja, critérios que procuram garantir melhor conforto, segurança e bem-estar aos usuários. Além disso, são sugeridas outras avaliações que analisem dados qualitativos e quantitativos com relação à postura, esforço muscular, distribuição de pressão nas mãos, pernas e costas, a fim de gerar dados objetivos, que auxiliem no desenvolvimento de melhorias para os produtos em questão.

\section{AGRADECIMENTOS}

O presente estudo teve apoio das agências financiadoras CAPES e FAPESP (proc. 2014/23953-6). 


\section{REFERÊNCIAS BIBLIOGRÁFICAS}

ABERGO. Norma ERG BR 1002 - Código de Deontologia do Ergonomista Certificado. Associação Brasileira de Ergonomia, 2003.

ABNT - Associação Brasileira de Normas Técnicas. Requisitos Ergonômicos para Trabalho de Escritórios com Computadores. 2002. NBR 9241 Parte 11 - Orientações sobre Usabilidade.

BEVAN, N. e MACLEOD, M. Usability measurement in context. Behaviour and Information Technology, n. 13, p. 132-145, 1994.

BROOKE, J. SUS: A Retrospective. Journal of Usability Studies, v. 8, n. 2, p. 29-40, 2013.

DILLON, A. Beyond Usability: Process, Outcome and Affect in human computer interactions. Toronto: Faculty of Information Studies, 2001.

GYI, D.E. Driving Posture and Healthy Desing. In: In: GKIKAS, N. Automotive Ergonomics: DriverVehicle Interation. CRC Press: Taylor \& Francis Group, 2013. p. 123-131.

HAN, S. H.; YUN, M. H.; KWAHK, J.; HONG, S. W. Usability of consumer electronic products.

International Journal of Industrial Ergonomics, v. 28, n. 3/4, p.143-151, 2001.

IIDA, I. Ergonomia: projeto e produção. 2a . ed. Rio de Janeiro: Edgard Blucher, 2005.

IKEDA, A.Y., PASCHOARELLI, L.C., DEGANUTTI, R. Desconforto percebido em condutores de veículos Baja. Parâmetros para o design ergonômico do assento. Anais ... VI Congresso Internacional de Pesquisa em Design (CIPED), v. 01, p. 01-04, 2011.

JORDAN, P. W.; THOMAS, B.; MCCLELLAND, I; WEERDMEESTER, B. A. Usability Evaluation in Industry. London: Taylor \& Francis, 1996.

MANSFIELD, N.J. Human Response to Vehicle Vibration. In: GKIKAS, N. Automotive Ergonomics: Driver-Vehicle Interation. CRC Press: Taylor \& Francis Group, 2013. p. 77-95

NIELSEN, J. Usability Engineering. Boston: Academic Press, 1993.

PARK, et al. Development of Statistical Geometric Models for a Driver's Hip and Eye Locations. Proceedings of the Human Factors and Ergonomics Society Annual Meeting. Sep 2013, vol. 57 no. 1, p. $1978-1982$

SAE BRASIL. Regulamento Baja SAE Brasil - Capítulo 1: Definições, 2010. Disponível em: <http://www.saebrasil.org.br/eventos/programas_estudantis/arquivos/RBSB_1_-_Definicoes__Emenda_0.pdf>. Acesso em: 13 jul 2016.

- Capítulo 5: Requisitos Gerais do Veículo, 2016a. Disponível em: <http://www.saebrasil.org.br/eventos/programas_estudantis/arquivos/RBSB\%205\%20\%20Requisitos\%20Gerais\%20do\%20Veiculo\%20-\%20Emenda\%203.pdf>. Acesso em: 13 jul 2016.

- Capítulo 9: Avaliações e Pontuações, 2016a. Disponível em: <http://www.saebrasil.org.br/eventos/programas_estudantis/arquivos/RBSB\%209\%20\%20Avaliacoes\%20e\%20Pontuacao\%20-\%20Emenda\%204.pdf>. Acesso em: 13 jul 2016. 
SILVA, D.; PLENTZ, B.P.; SALA, S.M.F.; MERINO, E.A.D. A Ergonomia na Identificação dos Aspectos Dimensionais Críticos: O Estudo Antropométrico de um Carro de Competição BAJA SAE. In. Human Factors Design (HFD), v.2, n.3, 2013, p. 3-19.

SCHULMANN, D. Introdução ao Desenho Industrial. São Paulo: Papirus, 1994.

TULLIS, T. e ALBERT, B. Measuring the user experience: collecting, analyzing, and presenting usability metrics. Burlington: Morgan Kauffman, 2008.. 